\title{
Blockchain in the university: a digital technology to design, implement and manage global learning itineraries
}

\author{
Pablo Rivera Vargas \\ pablorivera@ub.edu \\ Universitat de Barcelona, Spain \\ Universidad Andrés Bello, Chile \\ Carles Lindín Soriano \\ carles.lindin@ub.edu \\ Universitat de Barcelona, Spain
}

\begin{abstract}
Making universal access to education compatible with different paths of learning is one of the great challenges of the last century. Technology has provided solutions to access information, for communication and collaborative work. Blockchain emerges as a technology that can be useful for the development of an evaluation model of individualized learning itineraries in mass university subjects. In this line, the Edublocs project has been designed and executed, an initiative where these itineraries have been designed, incorporating elements of peer learning, teamteaching, PLEs, microlearning, technology-enhanced assessment...

The objective of the Edublocs project is to design and implement a system of recording the results of activities through Blockchain that allow the student to follow a personal itinerary, and the teacher-tutor of the subject to carry out a formative evaluation and an accrediting appraisal of their work. The project is well underway in the evaluation of the implementation process.

The experience with some elements of the design and the experimental execution in a formal university context during the present academic course, has allowed us to obtain important indications on the viability and relevance of the use of Blockchain in education. These, together with the explanation and justification of explaining the context of its applicability, will be laid out in the broad development of the article.
\end{abstract}

\section{Keywords}

Learning Itineraries; Blockchain in Education; University; Digital Education; Privacy. 


\section{Introduction: Blockchain and transparent learning activities}

The context in which the necessity to manage learning activities through Blockchain arises from the need to address individual differences in learning processes (Liu \& Ot, 2017), and, at the same time make it compatible with the accreditation mechanisms used in the formal education systems of today (Rivera-Vargas, Sancho-Gil \& Sánchez, 2017). The problem, however, focuses on how to evaluate different kinds of learning to different students whilst at the same time establishing some type of criteria that allows one to justify the accreditation of the student for having achieved certain skills, at a specific level.

It is, on the one hand, a practical problem. If the students follow different learning itineraries, how can the teacher evaluate all of them? The problem is not focused so much on summative evaluation but rather on a formative one, which relies on the monitoring of the student on a daily basis. It does not seem that this problem has been sufficiently solved in the last fifty years (Selwyn, 2016; Rivera-Vargas \& Cobo, 2018).

The inability to carry out a personalised follow-up even for groups that are not excessively large has led to the development of "machine-managed" solutions such as TEALE (Technology Enhanced Adaptive Learning Environments). In them, the work of the student is evaluated through computer systems, algorithms, and information gathered from large samples of students, and ultimately the itinerary to be followed is determined. However, these systems, based conceptually on an associationist vision of learning, encounter serious constraints for more complex learning. In addition, shortcomings exist in the social dimension of learning (Bartolomé, Castañeda \& Adell, 2018).

This current article is the result of the implementation of the Edublocs ${ }^{1}$ project. This is an initiative that seeks to develop a training model that allows different itineraries of students, where the four actors involved in the evaluation of the process, at different times and in different ways, guide in that itinerary. The four actors being the trainer, the subject, their classmates and the automatic systems.

Edublocs aims to design and implement a system of recording results of activities, together with the management of evaluation processes, through Blockchain. In this way, it enables the student to follow a personal itinerary, and the teacher-tutor of the subject to make a formative evaluation and an accrediting appraisal.

Bearing in mind each of these aspects, the question that guides the writing up of this work is the following: what are the possibilities and limitations of the use of Blockchain in the management of the evaluation of learning itineraries?

The preliminary results of the implementation of the project at the University of Barcelona are presented in this paper. From this introduction, the article has been divided into four sections. The first presents a conceptual approach to Blockchain and its possibilities in the field of education. At the same time, the Edublocs initiative is described, introducing its design, components and implementation process. In the second section of the methodology, the main characteristics of this preliminary evaluation are presented, and finally in the fourth section, the discussion and conclusions are carried out.

\footnotetext{
${ }^{1}$ For more information, visit the project's website: http://www.edublocs.org
} 


\section{General background}

\section{a. What is Blockchain? Why the use of Blockchain in education?}

Probably the most relevant aspects to maintain a level of trust in the digital world are: confidentiality, integrity and non-repudiation of the interchanged information. As Tapscott \& Tapscott (2016) state, confidentiality implies that information is not released to unauthorized individuals, entities or processes. Integrity implies maintaining information in a complete and accurate manner throughout its life cycle. This means that the data cannot be modified in an unauthorized or a detected way. "Non-repudiation" implies that neither the receiver nor the sender can deny having received or sent the transaction respectively. Since the emergence of the Post-Industrial Society, to what we know today as the Digital Society, a series of initiatives have proliferated endeavouring to provide security and legitimacy to the economic, political, social and cultural interactions that take place in the virtual world (Selwyn, 2015 \& 2018).

Nowadays, we find ourselves with a new strategy that in some sectors is known as the great tool we hoped to face this need for security. For some specialists (Tapscott \& Tapscott 2016), the possibilities that Blockchain offers in terms of security, agility and transparency of information in the digital world, would give it the power to drastically transform not only the financial services industry, but other diverse aspects of our society too.

In technical terms, Blockchain is recognized as a new disruptive technology in the registration of events through a distributed and replicated system (Bartolomé, 2017). This is especially true in the financial world, where cases like the Bank of England, as well as Visa, Santander, UBS, BNY Mellon, Deutsche Bank (Underwood, 2016) are just a few examples. In any case, the term can encompass several interpretations. Some use it to describe how to record and store the transactions of some cryptocurrencies (Narayanan, Bonneau, Felten, Miller, \& Goldfeder, 2016), while others use it to describe some specific components of a Blockchain environment, including the rules that determine the behaviour of such a system (Tapscott \& Tapscott 2016; Bartolomé, 2017).

Blockchain is composed of a set of applications, with special emphasis on the cryptocurrency, and in particular the BitCoin, the most recognized digital currency in the world. The success of Bitcoin is explained by the use of a decentralised system based on tests that are registered by all users, maintaining their anonymity (Wright \& De Filippi, 2015; Iansiti, and Lakhani, 2017). This attribute has permitted the emergence of a general interest for analysing the potential of Blockchain in fields as diverse as digital identity, attention to marginal groups, medical records, and of course, education.

Its emerging use in education has attracted the attention of educators and researchers in the field, that somewhat look suspiciously on it as regards the shortcomings and risks of this technology in education, although they also highlight some of its possibilities.

In this regard, in 2017, the University of Nicosia became the first higher education institution in the world to certify its diplomas through Blockchain. But the best-known projects are those generated from MIT and the UK Open University (OU). At MIT's MediaLab, Philipp Smith, director del Learning Innovation, developed a proposal for registered certification through Blockchain on an open standard: the Blockcerts. At the OU, Mike Sharples and John Domingue, both from The Knowledge Media Institute, tried, in the short term, to create a system for recording learning, using Open Badges, and generating a coin (token) of 
knowledge. Along with these initiatives, as from 2017, progress has been made in several lines of work.

\section{b. Edublocs: "adaptative" learning based on people}

The Edublocs project is an initiative promoted by researchers from the Institute of Research in Education at the University of Barcelona. The initiative seeks to promote a training model that allows different itineraries of students, but in which the four actors that can best, at different times and in different ways, guide in that itinerary. The actors of the evaluation of the subject are: the trainer, the subject itself, their classmates and the automatic systems. Parallel to this, there emerges the necessity to offer the student body diverse and comprehensive scenarios, activities and resources to favour their learning.

Since the development of the first multimedia courses, the problem of the in-built cost and the production of a sufficiently rich offer to respond to the needs of different students became evident. Learning objects (from now on LOs) represented a solution to the problem (Wiley, 2000). But the problem that arises from the costs of their encapsulation, the initial multiplicity of standards, and the natural evolution of the Internet have reduced them to a symbolic presence. It should be added that, in many cases, these objects could better be called "knowledge" than "learning" since they were limited to feature contents.

On the contrary, the Net has been flooded with numerous spaces in which to find resources for learning. Some are organised spaces, such as Khan Academy or Ted Ed. In other cases, they are resources framed in training programmes like the OCW or some MOOCs. We also have the resources generated and shared in open mode by numerous educators around the world, for example, through Youtube (Kurilovas \& Ot., 2014).

All of this lacks a complete training structure: objectives, levels of access, mechanisms of assessment, consisting in many cases of didactically organised contents (Thomas \& Brown, 2011), and are still far from being transformed in initiatives that deliver answers to the knowledge needs that must be met in the digital society, in line with what was proposed by Fullan \& Langworthy (2014) regarding new pedagogies and Deep Learning.

On the other hand, this whole approach focuses on the production of "digital" objects for online learning. This leaves to one side learning spaces as valuable as seminars, discussion groups, conferences, exhibitions ahead of colleagues, "fairs", and a long list of many other highly valued strategies today.

With all of this, the Edublocs initiative had to therefore include the elements of a formative design (for a specific element), but at the same time, not leave aside any of the possible learning strategies. So, first of all, the objective of the Edublocs project is presented. Secondly, the main organisational and structural characteristics of the implementation of the initiative. And thirdly, the evaluative proposal of the LOs is described.

\section{b.a. Objective}

This part of the project endeavours to implement through Blockchain a management system for the evaluation of the LOs that support the activities of the students, and that make up their personalised itinerary, different in the case for each one.

This implementation faces technological challenges so that the system responds to pedagogical needs. There is no previous documented experience since the use of Blockchain in Education in the three years that have elapsed since the University of Nicosia released its certificates or the MediaLab (MIT) initiated the blockcerts project, has focused on the 
certification of academic accreditation. The line developed in the last two years from the OpenKnowledge Center (Open University), although aimed at the certification, comes from small training packages that can form an academic curriculum on demand. The application of Blockchain to the certification of activities has barely been documented at the time of writing these lines.

Finally, the main goal of the project is to design and implement a system of recording the results of activities, together with the management of evaluation processes through Blockchains. In this way, it is possible to empower the student to follow a personal itinerary, and the teacher-tutor of the subject to make a formative evaluation and an accrediting appraisal.

\section{b.b. Structure and the implementation of the proposal}

The plan of itineraries was organised through what was initially called "LOs", and later, "activities" to avoid confusion. Each activity includes a design involving the following: its intended objective, a detailed description of the activity, the expected products, the evaluation procedures with the criteria that will be applied, and any other necessary information to be able to make a decision on it. In addition, each activity offers indications about the previous requirements. And, above all, each activity has a signature: a trainer who designs it, and who will make a follow-up on the students who carry out this activity.

In our case, five types of activities organised in blocks were offered. The student body had to perform at least one activity in each block, and a maximum of eight in total. The blocks corresponded to:

1. Group seminars

2. Development of skills in the use of specific technologies

3. Participatory conferences

4. Presentation of a symposium

5. Writing up an academic article

While some blocks $(1,3,4)$ are programmed on specific dates, others $(2,5)$ were developed over a long period of time.

\section{b.b.a The teacher-tutor}

In the formal university system in which we are located, the student body is organised into "class" groups of 40 students approximately. The educational institution assigns each group a teacher, who is traditionally responsible for "teaching" and "evaluating" the students (López-Pastor \& Ot., 2012).

In the Edublocs project, the teacher-tutor guides the student in choosing the itinerary, with the help of the results provided by an initial test, and through a process of dialogue/negotiation with the subject. It also follows the student during the process, both in terms of changes in the itinerary, and to guide the overall level of the student. And at the end of the process, based on the assessment provided by the trainers responsible for the different activities, as well as the dialogue with the student, summative assessment is provided that will be transferred to his/her official results.

This is one of the elements in which Blockchain is key in the design. Each teacher-tutor must accept the assessment given to each of their students by the trainer responsible for each activity. It is necessary to fully trust that the information received is reliable and has not 
been modified. In our experience, this would have been easily solved from the moment that all the teachers involved belonged to the same educational institution and department. But when, later on, we understand (and develop) the global dimension of the project, we will understand the need for a distributed, reliable, secure, horizontal system to manage these records.

\section{b.b.b The social dimension}

In the absence of formal "class groups", one might think that students work individually, thus losing the social dimension of learning. This is not the case; not only is collaborative work enhanced in the activities that are directly evaluated in groups (seminars, presentations at the symposium) but also those that are subject to individual evaluation (blocks 2 and 3).

However, these groups do not respond to the "formal team" model which is characteristic of other educational designs, but rather they reproduce the functioning in social networks, in which collections of people form groups or limited "networks" (for example, in WhatsApp, a Twitter list or a Facebook group) (Rivera-Vargas \& Miño-Puigcercós, 2018). These groups, on the other hand, are formed by students from different "class groups", and may vary from one activity to another. They are a "causal" group that is organized for a specific purpose at a specific time and that, as happens in networks, they have a diffuse character of belonging, although, obviously, it is also possible to establish more stable, strongly cohesive groups.

The design is especially useful for students in the first year/first semester of the studies, but its objective is to respond to the need that not all group members follow the same itinerary or perform the same activities.

\section{b.b.c A design for a global dimension of training}

Everything seen so far could be resolved through a tool shared by the three teacher-tutors involved. In this project, the TEA was developed, an evaluation tool that allowed to act with the different roles of trainer and teacher-tutor, with all the students. It would be another example of Team Teaching.

But the project has another vision (Lata, 2017). In the current situation, the offer of activities will always be limited. But let's consider another scenario. Teachers of similar subjects or close to different educational institutions and countries act as "trainers" offering one or two activities. On the other hand, these same or other teachers of different subjects, also in educational different institutions, act as "teacher-tutors" and guide their students, with the help of initial tests based on the indications of those activities they consider relevant for their group, and negotiate itineraries.

Each student performs different activities, guided by "trainers" who can be anywhere in the world, and who assess them by providing a grade on an agreed scale. Each "teacher-tutor" consults the Blockchain on the results obtained by each one of their students in the different activities; they give them a weighting and significance within the framework of the subject, and a final grade is produced.

Of course, this could be solved with a centralized system, through a database, conveniently protected, in a secure server. But Blockchains are precisely offered as an alternative to these systems, offering greater reliability, greater security and greater privacy. 
It is important to point out that teacher-tutors as well as trainers do not need to form a structure, nor register in a space, and they do not need to negotiate a program or even work on the same subject. The Blockchains ensure the reliability of the grades corresponding to each activity, while the selection process of the available activities by the teacher-tutor ensures its validity and its adaptation to their specific program. But, in addition, we have discovered that they also offer greater transparency throughout the project.

\section{b.b.d A transparent system that respects privacy}

The Blockchains are accessed easily, unalterable, nevertheless, are also private. This characteristic has been used in the project to offer students the possibility of consulting at any time not only their grade in a specific activity, but also its meaning in the context of those of other students who have performed the same activity. However, the identity of the students is always protected, except for the student who makes the query. Likewise, they allow a system of certificates that students can use with future teachers or with future employers, to accredit specific learning. These certificates are secured by the Blockchain, since they are unalterable, persistent and private unless the student wishes to show them.

Once again, we must consider the scenario of the global project. Internally, from an educational institution, this could be solved through centralized databases, but when the student has carried out activities generated by trainers in different educational institutions, the certification process through Blockchain exhibits all its potential (Chen, Xu, Lu \& Chen, 2018).

The design of the program also includes other important elements, but those indicated here allow us to understand quite well how the problem of the individualization of the learning itineraries is faced, offering at the same time a new global training model, and how the Blockchain helps to manage this design.

\section{b.c Learning objects and evaluation}

Since the beginning of the nineties, Wayne Hodgins conceived learning objects as "easily interoperable learning pieces" (Hodgins, 2002: 6). Those that have been accepted as the solution to the design of training in virtual environments, have been subsequently abandoned and redefined. And throughout this process, the evaluation of the learning achieved with the object has been one of the key elements of the problem. The evaluation of the student, both in its formative and accrediting aspects, is a competence of the teacher or tutor responsible for the subject. However, many authors have pointed out that this evaluation is linked to the object:

"If learning objects are constructed from a pedagogical perspective oriented to the scope of a specific learning objective, the evaluation must be included in this approach from the beginning, since we are building learning sequences that should contemplate evaluation as part of the training itinerary. "(Guàrdia \& Sangrà, 2005: 4).

But this has only been possible insofar as the learning objects lost their character as an open resource and were a way of organizing the production of contents in a closed educational institution. This is the case analysed by Guàrdia \& Sangrà (2005).

The reasons being several and some are of an economic type. The objects available in open mode in the network have assumed a specific cost that is affordable, but if the designers of the objects must also be responsible for the evaluation of students who, coming from other educational institutions or companies, use those objects, they should be remunerated for their work. 
Others are of a pedagogical nature: the evaluation in a training program is a complex process in which the trainer-tutor is either there to guide the student in his/her journey or to prove that he/she has achieved certain objectives or competencies. From this perspective, it is problematic that the evaluation is subject to the criteria that a stranger has designed, perhaps from another epistemological or didactic angle.

The consequence is that the learning objects available in the open network rarely include the evaluation of learning. And the same happens with learning resources, a more flexible variant where we can include videos or other types of documents downloadable from the network and available through standard search engines to even those that offer more or less consolidated repositories such as Merlot $^{2}$ or Khan academy ${ }^{3}$.

Even the repositories that include evaluative items such as EdTed ${ }^{4}$, do so under the heading of "reflection", understanding that the evaluation is in the hands of the trainer or tutor responsible for the subject.

The solution adopted in this project has consisted in distinguishing between two traditional concepts of educational evaluation that have often been confused: the assessment of the results of an evaluative metering; and the evaluation process of the student, both formative and accrediting. To understand what follows, we will use these terms "assessment" and "evaluation" appropriately from here on.

In this perspective, the evaluation and assessment of the learning achieved in an object, according to the objectives pursued, is an activity related to the object, proposed and that must be carried out by the actor responsible for the object, that is, the one who offers it in open mode on the Net. On the other hand, the evaluation of the students' learning process, their progress and, lastly, the final achievement of the objectives or the development of the intended competence is a task that corresponds to the person in charge of the training program in which the students participate.

Once both processes have been distinguished, on the one hand, the evaluation and the resulting assessment of the learning achieved by the student in an object, and on the other, the formative or accrediting evaluation, we will then call the agent responsible for the first task "trainer", since it is in charge of the learning linked to the object. The agent responsible for the evaluation of the student as a whole will be the "tutor". We could choose other names like "instructor" or "teacher" for the first function, and "facilitator" for the second.

It is possible to refute that an instructor is not necessary for a learning object. This is erroneous: the instructor can be a machine or a person, but if the object includes some kind of assessment of the learning, it must be done by someone (or something) responsible for that learning. Learning objects have not been designed (or at least not exclusively) for autonomous learning situations. In fact, the LOs in closed environments such as those proposed by Guàrdia \& Sangrà (2005) are characterized precisely by having an instructor, that coincides with the tutor of the subject.

This is the moment when we need the Blockchains to assure the management of the differentiated itineraries. The tutor agrees on an itinerary with their students, allowing them to choose a certain LO offered on the Net; an LO that includes an assessment of their learning needs:

\footnotetext{
2 https://www.merlot.org/merlot/index.htm

3 https://es. khanacademy.org/

${ }^{4}$ https://ed.ted.com/
} 
- Trust the validity of the assessment that will be provided by the instructor of the object

- Trust the reliability of the mechanism through which this information arrives

- Have an integration system available of this assessment in its evaluation system

It is worth recalling that the LOs in Edublocs are offered on the Internet by experts or academics from educational institutions around the world and not by members of the same educational institution as the tutor. In this perspective, the first point follows a process similar to the one existing today on the Internet. A recent proposal (Gräther et al., 2018) uses a hierarchical system: accreditation authorities that validate the certification authorities, which are the ones who finally introduce the accreditations in the blockchains. But this system does not differ much from the traditional system of academic authority, which also does not differ substantially from the index of prohibited books, in which the ecclesiastical hierarchy pointed out what knowledge was valid or not. This mechanism was proposed by Dominique Wolton (2000) at the beginning of this century, suggesting the creation of a censorship committee made up of journalists that indicated what could be published or not on the Net.

However, the concept of the authority of the expert has changed on the Internet: it is the user who grants validity by accepting a unit of content (Bartolomé \& Grané, 2013). In the same way, it is the tutor who, using similar criteria (coherence and the substance of the text and reliability of the author) accepts a certain LO to be integrated into the itinerary of his/her students.

In the absence of a common structure in which tutors and trainers interact, the process to get the assessment of one another becomes vulnerable. This is where Blockchain provides a robust recording system, resistant to attacks, that supports privacy and does not require a centralized system to manage the grades. This will be the objective of our study.

Regarding the third point, our proposal uses a system of flexible and powerful weighting factors, dependent on both sides of the process, tutors and trainers, but whose final application depends on the tutor. These weighting factors are those that allow the transfer of the evaluations granted by the trainers (in the LOs) to a formative or accrediting evaluation in the hands of the tutor. The three factors are: complexity and difficulty of the object, factors that help the tutor to assess their weighting in relation to other objects, and their relevance in the framework of the training program. The same object may be highly relevant in one subject, but may only be of secondary importance in another.

\section{Methodology}

The Edublocs project is in its full implementation phase during its first year. In order to analyse this initial phase, an Implementation Evaluation has been carried out (Lázaro \& Obregón, 2009) ${ }^{5}$, in order to make improvements that may favour the sustainability of the initiative. According to Lázaro \& Obregón (2009), this type of evaluation "aims to assure that the implementation of an initiative is carried out properly and in line with being able to achieve the expected results" (pp. 5). In the same line of Sapag \& Sapaga (2000), what we are searching was to observe and assess each component of the project, using the same information generated in their own resources and dynamics that are generated in the initial implementation of Edublocs. It was therefore a matter of evaluating if the project was being

\footnotetext{
${ }^{5}$ It is also defined as the Evaluation of the Process of Implementation by Sapag \& Sapag (2000).
} 
organized and managed correctly, that is, if the set of production factors or critical functions of the organization operate with the consistency and coherence to meet the initial objectives.

The results of this exercise have an immediate interest in the process to redirect it if necessary, while providing us information that is part of the general validation of the project. Although the project includes several elements in the teaching design, including the four already indicated, this article focuses on the implementation of a certification strategy based on Blockchain for the management of the itineraries.

\section{a. Process of collection and analysis of information}

As we have already mentioned, this article is the result of the Implementation Evaluation of Edublocs, which has been carried out to follow up the process of design, development and implementation of the initiative. What is done following the line of Padilla (2016) has been to know the development of the project, the problems that have arisen, the solutions found and the exact dimensions of unresolved problems.

In this sense, the proposal of Lázaro \& Obregón (2009) on the Implementation Evaluation of projects, suggests that the greatest possible amount of evidence should be kept in mind in order to analyse the different dimensions involved in the smooth and successful running of a project. In this regard, what is presented here is the joint analysis of a multiple body of evidence that has been obtained from a mixed use of information gathering strategies.

For Lázaro \& Obregón (2009) and Padilla (2016), one of the essential sources for carrying out this type of evaluation is represented by its own specific documentation of the initial management of the project. We refer to the minutes of the organizational meetings, the emails, and all the supporting documentation of the agreements reached. In our case, throughout the process, which began with the first meetings in February 2018 and continued with the beginning of the course in September (2018), and ended at the end of the course in the month of December (2018), detailed reports were written up explaining the problems detected and the decisions taken. This was done thanks to the fact that each of these instances was recorded and transcribed. A copy of the most significant epistolary exchanges (email) made during the months between September and December (2018) has also been kept, in which it was possible to follow the process by which a certain decision is reached.

All this process has been complemented with the analysis of the technical reports that were generated from the management of the app itself, explaining a change or a new application in the platform.

With the information sources that have been obtained, a process of grouping evidence has been undertaken (Holstein \& Gubrium, 2000) which has led us to generate a single corpus of content. This, in the line of Raigada (2002) and Scribano \& De Sena (2009) have allowed us to provide an integral account of the body of evidence and therefore respond to the question posed in the introduction of this article. The results have been organized into two central dimensions of analysis. The content that composes each one of these dimensions is expressed in a narrative way as a systematization of experience (Holliday, 2012), which entails the integration of sources of information, with the comments and reflections of those who write this article.

\section{Results}

The results presented below give an account of the implementation evaluation carried out in the fourth month of implementation of the Edubloc initiative. As we have mentioned, the 
results have been grouped into two large dimensions, integrating the data and information obtained in the process in each one of them. These are:

- Analysis of the process: Evolution of the design

- Remaining problems

\section{a. Analysis of the process: Evolution of the design}

The development of this dimension was approached from six subdimensions that give an account of the design process, associated costs, certification and evaluation of the Edublocs project.

\section{a.a. The design of the platform}

At an introductory level, we emphasize that the whole process that has been carried out is based on the "Edublocs Grade Book" (EGB), which has been created especially for the Edublocs project. This $\mathrm{EGB}^{6}$ allows the permanent registration of the information of grades. This information is verifiable, universally accessible and resistant to modifications or deletion attempts. The EGB is public and can be viewed in any browser on the default page or on the pages for specific tasks.

In practical terms, anyone can add new records to the EGB. All you need is an Ethereum ${ }^{7}$ account with enough credit to pay for the transaction. However, we have used MetaMask ${ }^{8}$ to manage the account and private passwords. Although it can be installed in different browsers, in our project the tasks have been carried out in $\mathrm{Brave}^{9}$, a secure browser based on Firefox and with the MetaMask plugin installed. When a key is required to execute a certain transaction (basically a record), a MetaMask window is automatically opened in the browser to confirm the operation.

The EGB facilitated the introduction of records to the trainer, acting as an intermediate step between Ethereum and the navigator. Introducing a record was a task in which the trainer responsible for the LO only needed to complete a simple form on the web (figure 1 ).

\footnotetext{
${ }^{6}$ https://edublocs.github.io/eb-webapp

7 Ethereum is a Blockchain with a fully integrated Turing programming language, which allows anyone to write intelligent contracts and decentralised applications by simply writing the logic in a few lines of code.

More information in the following link:

https://www.ethereum.org/

${ }^{8}$ https://metamask.io/

${ }^{9}$ https://brave.com/download/
} 


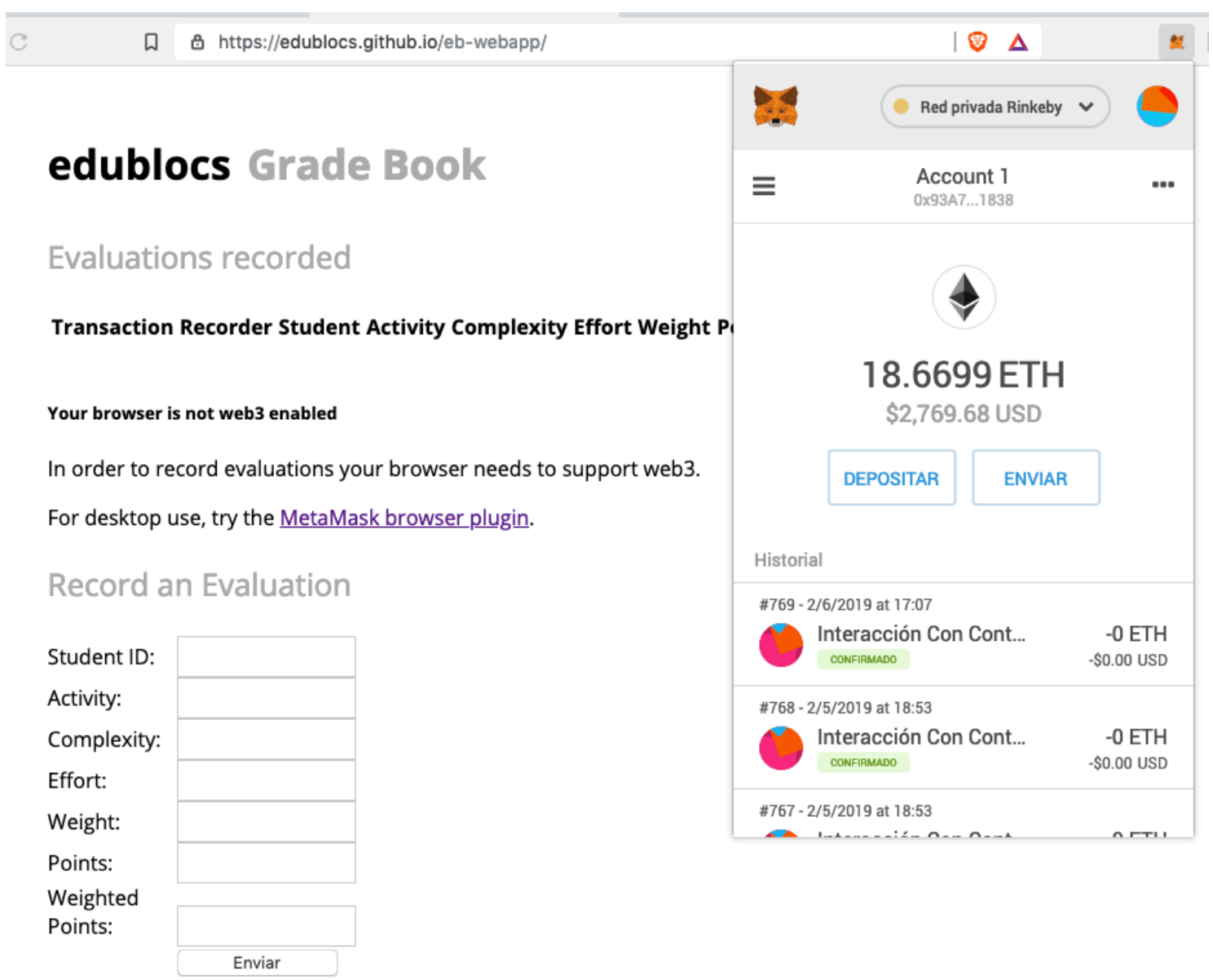

Figure. 1. EGB interface, with the form for the introduction of a record. On the right, the Rinkeby private network widget, which allows confirmation of the transaction.

Source: the authors

However, this was an additional step for the teacher who would be working in their usual management environment, which was opening the browser and transferring the data. If we also take into account that, once the information was sent to Ethereum, the construction of the block and consolidation of the record were not immediate, it was thought to resort to a double step to simplify the task of the trainer.

With the EGB, the trainers can ignore the most cryptic aspects of the process, such as the generation of smart contracts or the encryption of the blocks. In this way, we could facilitate a smooth process. Indeed, for the consultation of the results by the students, this double step became necessary, since the information in Blockchain is protected by a private password. Normally, in many Blockchain applications in the social fields, that password belongs to the owner of the information (e.g. the identification data of a person), who is the one who records the information and who can reveal it. In our project, however, the records (the grades) are introduced by the LO trainers, and the consultations are carried out by the tutors who evaluated the groups as well as the student themselves.

In other projects (Gräther \& OT. 2018), the solution has also included a double step: the agent that accesses the Blockchain is the educational institution that accredits and/or validates it. When the student wishes to certify a unit of learning, he/she goes to the educational institution which is the one that issues the certificate based on the records of Blockchain. And this was the strategy that was adopted here, and it is explained hereafter in point a.2. 
This double step does not solve the problem of recording by the trainers and consultation by the tutors. In the pilot version of the project, a problem did not occur because both of them used a common tool within the framework of a common educational institution. The TEA app solved the problem, but does not solve it in a scalability intended in future phases, in which there is no common institutional umbrella.

\section{a.b. Design of double step}

One part of the Edublocs project involved the development of a management tool of team assessment by the teachers. The application was called TEA (Technology Enhanced Assessment) (figure 2).

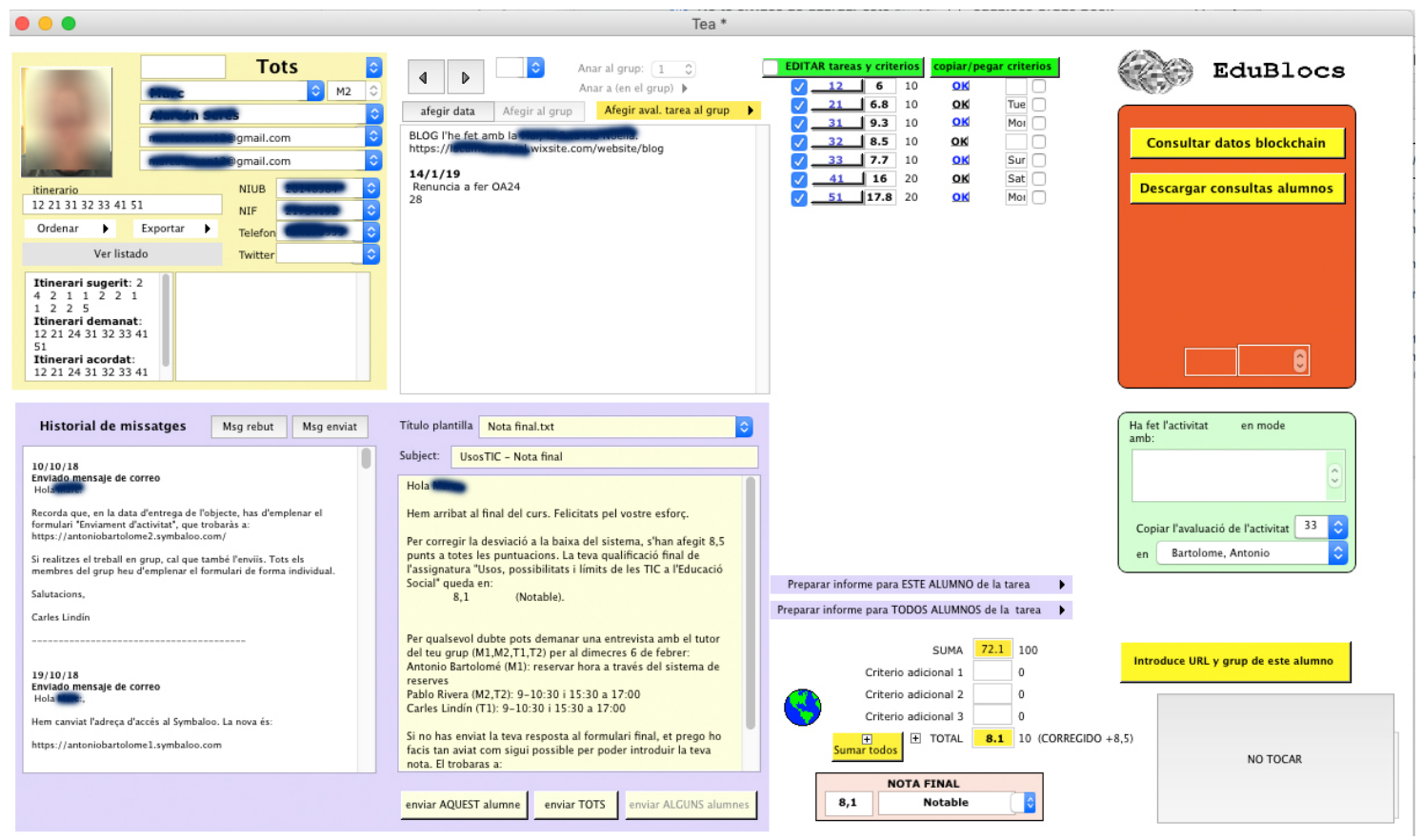

Figure. 2. TEA App.

Source: the authors

This app allowed not only to manage the assessment of the LOs but also to manage communication with the students, reducing time and simplifying efforts. Therefore, a resource was introduced that allowed this app to generate the form, only leaving the task of confirming the record on the Net.

As we can see in the red area to the right of figure 2, the TEA has a section that includes the basic query buttons and Blockchain records. The first destined to be used by the tutors, and the second ones by the trainers.

In the final operation, it was decided to transfer temporarily those buttons to an external application. It was a mere technical change. TEA was used by teachers allowing the possibility to work in local mode and, at the same time, Net synchronization (following Dropbox protocols). It was a self-running application that worked on student records in shared spaces. The implementation of Blockchain control buttons in experimental mode could generate malfunctions in the application. However, once used, its incorporation into the platform is immediate, and does not require extra programming.

A double step was also used for the students. Although the query did not require a special browser or MetaMask (since it was open), the student's identification was hidden behind a 
secret number. For them, a consultation results page ${ }^{10}$ was designed in the LMS, in which it was enough to enter their password to access the information in an easy and friendly environment.

Since the students did not have the private password of recording on Blockchain, the records identified the students by means of personal passwords. This password allowed them to make inquiries quickly and securely. They could also go directly to the EGB, but in that case they would have to extract manually those that corresponded to them from the lists of the records in Blockchain.

\section{a.c. The economic costs}

One of the most frequent criticisms made of Blockchain is its high cost. Although the course was held between September and December 2018, the first tests took place in April and May of the same year. At that time, according to the value of the ETH, each registered student had a cost of $€ 0.15$ and each record cost $€ 0.25$.

Calculating for 160 students and 10 activities per student, this amounted to $€ 440$, with an average cost of $€ 2.65$ per student. This was a perfectly acceptable cost and is easily scalable: a student who covered 60 credits of an academic course with 10 subjects working with a similar system would have a cost of $€ 26.50$. This represents between $1 \%$ and $2 \%$ of the amount of their registration.

This cost is lowbut, as it is a pilot implementation, it was decided in September to work with a testing network on Ethereum called Ropsten ${ }^{11}$. The ETH for the payment of the transactions can be acquired without cost. In return, these records are not incorporated into Ethereum, which we found interesting given the experimental nature of the study. Later, during the implementation, we worked with another private Net called Rinkeby ${ }^{12}$.

To understand this technical change, we must remember that Blockchain and Ethereum are very recent and constantly changing technologies. The test networks are subject to problems arising from these changes. This is what happened with the Ropsten network, since the problems were detected when they began to introduce the first mass records, corresponding to LOs 11, 12 and 13. The company that developed the EGB suggested the best solution was to change the network. This just meant the reintroduction of 20 new records in the new network.

\section{a.d. The design of the record}

An important task of the project was the design of the record: what values and in what format each record would contain. The design should be flexible enough to adapt to future changes, and not so long as to increase costs. The final design was the following ${ }^{13}$. Each record contained the identifier of who entered the information, the student to whom it corresponded, the evaluated activity, and five values assigned to the weighting of complexity, effort, relevance in the subject, grade obtained and weighted grade (table 1 ).

\begin{tabular}{|l|l|}
\hline Recorder & $\begin{array}{l}\text { is a string of } 42 \text { characters with the format } \\
\text { 0x553b2c3853b10f90303b5fd01c70b067413f6c46 }\end{array}$ \\
\hline Student & $\begin{array}{l}\text { String of characters; there is no practical limit, but the cost one: the } \\
\text { longer, the higher the cost of registration }\end{array}$ \\
\hline
\end{tabular}

${ }^{10}$ http://www.Imi.ub.edu/edublocs/

${ }^{11}$ https://faucet.ropsten.be/

12 https://www.rinkeby.io/\#stats

${ }^{13}$ The calculation of costs is based on this design. 


\begin{tabular}{|l|l|}
\hline Activity & 0 a 4294967295 \\
\hline Complexity & $0.0-10.0$ \\
\hline Effort & $0.0-10.0$ \\
\hline Weight & $0.0-10.0$ \\
\hline Points & $0.0-10.0$ \\
\hline Weighted Points & $0.0-10.0$ \\
\hline
\end{tabular}

Table 1: Design of record

Source: the authors

These limits $(0-10)$ are entered in the EGB. In Blockchain, the record works between 0 and 255. This nuance is interesting because it means that in reality, they could be between 0 and 25.5. And this was used months later when a scale of 0-20 was used for the grading of activities 41 and 51. A simple change in the interface allowed the use of the new grades.

\section{a.e. From the assessment of the LO to the evaluation of the student}

The teacher-tutors could at any time consult the students of their group and check their progress in the proposed itinerary. In addition, it allowed them to make changes to the itinerary and have a vision of how they were progressing. To do this, it used the same TEA platform as the LO trainers. This does not need to be the case and both of them can use other evaluation management systems and other LMSs. The point of union is the record of the assessment of the LO in Blockchain.

Indeed, the difference of the processes was clearly shown in this tool. For example, while the tutor could access the grades that the different trainers recorded for their students, and the overall grade that would be obtained at any time in the process, this did not automatically identify with the evaluation of the subject. The tutor could use other additional indicators to construct their own evaluation reports. The most paradigmatic case is that of the final grade. Once the tutor introduced his own correction elements to the assessment received via Blockchain from the trainers of each object, even at that moment, the final grade was not generated automatically, but rather the tutor made an informed decision and graded the student.

\section{a.f. Certification of learning: beyond that of a course}

The certification of the activities in an independent way - one by one - through Blockchain, allowed an additional resource. A student could certify in successive courses in front of teachers of other subjects that a certain topic, resource, competence or activity had been carried out (and the level reached) through the records in Blockchain.

To this end, in the student's consultation page that allowed the comparing of results with their peers and perception of how they worked, it was decided to add the option of obtaining a certificate of the work in any one of the activities.

In the record that is obtained from the use that the students make of the direct consultations to Blockchain, we find 1204 queries for a total of 133 subjects. Of these, only 33 corresponded to these certificates. In this data, it was observed that the majority of the consultations focused on the grades and these in relation to their classmates. There were 67 
consultations on matters related to the self-regulation of learning, a relatively insignificant number.

\section{b. Remaining problems}

Considering that the next phase of this project involves expanding the process with the participation of other educational institutions and teachers, we ask ourselves: What are the remaining problems? This question is very relevant because in this first implementation phase it can be stated colloquially that it was "playing it safe", that is, at any given time, a problem could be solved by teachers who were colleagues, and that had the same institutional culture and communicated through rapid and direct channels.

Therefore, the analysis tries to find what elements would not have worked in that scalability of the system, although in this pilot study it could possibly be something that is easily solved. In this sense, we find four aspects that are worth taking into account, and that we will now outline.

\section{b.a. The immediacy of the processes}

Recording on Blockchain is secure, transparent, but slow. Each time a record is added, it must be integrated into a block, encrypted and added to the string. In between, smart contracts will be generated and various technologies will act.

To sum up, we have found that the recording in Blockchain of some data involves between 20 and 60 secs. When several records are introduced (for example, the records of the same activity corresponding to several students) it is possible to resort to management techniques that make the waiting more bearable. But, in general, it is a process that teachers find slow, accustomed to the fact that introducing a grade is something that is reasonably fast.

The situation becomes complicated when the data is consulted. In this case, the download (any decryption) of all the records corresponding to at least 140 students can take more than 10 minutes. From this complete table, the system can calculate means and offer the student data and comparative analysis with their peers.

Keeping in mind that the system acts as an intermediary in two steps for student consultations as explained before, the solution chosen for now is that the download of all the records is done periodically, and not at the moment in which the student poses the question. In this way, the answer to the student is immediate. But, on the contrary, the information may not be updated. It could happen that the last records (the last activities carried out by the student) have not appeared yet.

This is a problem that had not appeared until now in the literature on Blockchain applications. It may not be relevant in other applications. In the case of itineraries, this may not be a fundamental requirement either, but it is still a problem that has arisen.

\section{b.b. The recovery of information: The problem of the private password}

We have previously referred to this problem. In the case of students, it is not. They cannot access the private password; therefore, their certificates are always issued by an educational institution. This does not affect the possibilities of the Blockchains since they allow the generation of those certificates in the context of loose networks, and not within closed institutions. However, the problem is more complicated in relation to the trainers (who evaluate the LO and introduce their grades in Blockchain) and the tutors (who take those assessments as a basis for their evaluation, and to generate accreditations for their students). In Edublocs, trainers and tutors had access to the password. But this is not 
possible in their scaled system in which educators from different educational institutions (or even individuals) participate with one function or another.

Obviously, the key to encrypt should be in the hands of the trainers, since they are the ones who introduce the records. The tutors do not need that password to access the records, but they do need to know the identification codes of the students in order to be able to accredit them. With the current solution, all trainers use the same password to enter the records. It is true that there is a variable that identifies the trainer that introduces the record, but this permits the impersonation of one trainer for another. The use of identifiers is not enough, since a review of a not very large series of records is sufficient to quickly identify which is the password corresponding to another trainer.

Therefore, we need to resort to different encryption passwords, but that allow the tutors to consult without any password. This is a problem that is found in the EGB, and therefore the technicians should be queried regarding the procedure to be able to solve it.

\section{b.c. The persistence of information}

One of the most attractive options for students of this educational proposal, is the possibility of being able to prove in successive courses or even to future employers, certain acquired and validated learning. In the case of employers, it is more a theoretical problem than a real one, because the speed of changes in production processes today means that a specific unit of learning obtained five years ago may not be as relevant as it may seem (Masika \& Jones, 2016).

But in the case of other teachers, the situation is more interesting. In current study programmes, it is common that there are skills that are considered necessary in a subject, prior to the acquisition of others. A conscious teacher will perhaps try to confirm that his/her students possess those skills. But he/she will rarely be devoted to consult study programmes of other subjects and to discuss with teachers (apart from the fact that different teachers may have worked on different content or with different levels of depth in the same subject). There is always the problem of repetitions between subjects.

We have seen that this option has hardly been consulted by the students $(<3 \%)$, but it is also true that they have not found themselves in the situation of needing it, since the course just ended that semester. But if needed, is the network sufficiently persistent? At this moment there are more than 200 platforms that generate the corresponding cryptocurrencies, which could be used here. In our case, as we have mentioned, we use Ethereum. The less relevant can disappear in this process of initial development of technology. But such consolidated platforms such as Bitcoin or Ethereum are subject to external attacks too, which are not related to a project such as Edublocs, but which could potentially result in the loss of that information.

\section{b.d. The economic cost of the process}

We have already analysed the cost of the project. We have already seen the cost of the project this year was $€ 424$. It is a theoretical cost since finally it has worked with the Rinkeby ${ }^{14}$ private network. But let's scale the project once again. Although the cost is reduced, it does not stop being a cost. The most important problem arises in the distribution of the cost. The Edublocs project is based on the fact that a teacher or tutor of a group, acts as a trainer in an LO, assessing the students of other teachers. It is evident that it is possible to limit the number of students accepted. Attending to 300 students in an LO is not

${ }^{14}$ https://www.rinkeby.io/\#stats 
problematic from the moment in which, in other LOs, it benefits from the work performed by other trainers.

The distribution of work was not a problem in this pilot study. The course was finally conducted by 119 students, that were counted with an offer of 14 LOs. The distribution of students can be seen in table 2 .

\begin{tabular}{|l|l|}
\hline Learning Object & $\begin{array}{l}\text { No of students that undertook } \\
\text { each Learning Object }\end{array}$ \\
\hline 11 & 41 \\
\hline 12 & 85 \\
\hline 13 & 18 \\
\hline 21 & 28 \\
\hline 22 & 55 \\
\hline 23 & 48 \\
\hline 24 & 62 \\
\hline 31 & 104 \\
\hline 25 & 67 \\
\hline
\end{tabular}

Table 2. Number of students per Learning Object

Source: the authors

The three trainers that took on the tasks of evaluation had a relatively homogenous distribution in each one of the LOs, as can be seen in table 3.

\begin{tabular}{|l|l|l|}
\hline Trainer & OA evaluated & $\mathrm{n}$ \\
\hline Form 1 & $21,22,25,26,31$ & 202 \\
\hline Form 2 & $12,23,24,32$ & 262 \\
\hline
\end{tabular}




\begin{tabular}{|l|l|l|}
\hline Form 3 & $11,13,41$ & 177 \\
\hline
\end{tabular}

Table 3. Learning Objects evaluated by trainer

Source: the authors

Of the 14 LOs, there were two whose evaluation was carried out differently. In the case of LO 33, this was evaluated by the students themselves, so the role of the trainers was limited exclusively to coordination work. In the case of LO 51 , its evaluation was distributed among the three tutors, since it had the character of a final project assignment.

Considering that the trainer responsible for an object should pay the recording of the assessments made by the student body, as can be seen in table 4, the potential payment that would have corresponded to each trainer would have been as follows:

\begin{tabular}{|l|l|}
\hline Form 1 & $€ 86.08$ \\
\hline Form 2 & $€ 75.08$ \\
\hline Form 3 & $€ 53.83$ \\
\hline
\end{tabular}

Table 4. Payment potential of each trainer according to the assessment made by the student body Source: the authors

In relation to this data, the following question is posed: will the trainers be ready to take on this payment? Will a way to finance these expenses be found, apart from the special assistance grants linked to projects? It is true that they are not large quantities, but we are proposing a system that should work on a loose and global network of educators. Therefore, the challenge is to think about how this cost can be covered.

\section{Discussion and conclusions}

The Implementation Evaluation that we have carried out in the application of the Edublocs projects has allowed us to identify a set of significant elements that will surely be very useful in order to seek their sustainability. In relation to the two dimensions of analysis proposed, we can affirm the following:

In relation to the analysis of the process and the evolution of the design, we observe that, in general, the system works. Disruptions in the process have been solved and finally implemented. Nevertheless, from this pilot experience and the possibilities that this entails in terms of solving incidents and optimising processes daily, we believe that without Blockchain it would not be possible to design, implement and manage a learning proposal in a global environment as has been planned.

In relation to the problems that need solving, we note that that there are still some of significant importance. Of these, the ones that can most affect the future scalability of the design are:

1. The management of a different password system for the different trainers

2. Encryption in Blockchain is a slow process so it is essential to look for alternative solutions 
3. The costs connected with the design are not high, but it is difficult to find a way to make them acceptable for the educators involved

In February 2019, a new stage began which involves new actors and changes in the design are introduced that allow scalability.

Regarding the question raised in the introduction that guided the writing of this study: what are the possibilities and limitations of the use of Blockchain in the management of the evaluation of learning itineraries? We consider that the Edublocs project, through enabling the student to build their own learning itineraries, has encouraged the student to become aware of the potential contributions that the implementation of LOs can mean for their learning.

Finally, in relation to the use of Blockchain in the project, it has been possible to observe its potential, not only for the implementation of this particular initiative, but also the construction of personalised learning itineraries in a global environment. With students, teacher-tutors, and trainers of LOs from different organisations and countries, Blockchain offers a technological system that guarantees the identification of the different actors that make up the learning process, as well as the assimilated skills. In parallel, the information of the learning process is secure, legitimatised and validated by its actors, while being accessible in a global, secure and confidential manner. Therefore, the faculty could become a specialised trainer in courses offered in various educational institutions, instead of attending to various subjects that are quite similar according to the specific needs of each university. In addition, the student body would agree to direct their learning process in contact with international specialists.

It will be necessary to gather more information in the future about how the student body has performed with regard to the management of their evaluation. This is particularly interesting for how Blockchain allows one to know the evaluation by individual objects and in a global way with respect to all the objects implemented, both of an individual student and also of this student in relation to the group.

\section{References}

Bartolomé, A. y Grané, M. (2013). Interrogantes educativos desde la sociedad del conocimiento. Aloma. Revista de Psicologia, Ciències de l'Educació i de l'Esport, 31(1), pp.73-82. http://www.revistaaloma.net/index.php/aloma/article/view/173/115

Bartolomé, A. (2017). Cambiando el futuro: Blockchain y educación. Comunicación y pedagogía: Nuevas tecnologías y recursos didácticos, 303, 7-12.

Bartolomé, A., Castañeda, L. \& Adell, J. (2018), Personalisation in educational technology: the absence of underlying pedagogies. International Journal of Educational Technology in Higher Education, 15 (14), 1-17. doi: http://doi.org/10.1186/s41239-018-0095-0

Bland, D., \& Atweh, B. (2007). Students as researchers: engaging students' voices in PAR. Educational Action Research, 15(3), 227-249. Retrieved from: http://www.tandfonline.com/doi/abs/10.1080/09650790701514259

Chen, G., Xu, B., Lu, M., \& Chen, N. S. (2018). Exploring Blockchain technology and its potential applications for education. Smart Learning Environments, 5(1), 1-10.

Fullan, M., \& Langworthy, M. (2014). A rich seam: How new pedagogies find deep learning. London: Pearson. Retrieved from: https://www.michaelfullan.ca/wp-content/uploads/2014/01/3897.Rich_Seam_web.pdf

Guàrdia, L. \& Sangrà, A (2005). Diseño instruccional y objetos de aprendizaje: hacia un modelo para el diseño de actividades de evaluación del aprendizaje on-line. RED: Revista de Educación a Distancia, (4), 1.

Gräther, W., Kolvenbach, S., Ruland, R., Schütte, J., Torres, C., \& Wendland, F. (2018). Blockchain for Education: Lifelong Learning Passport. In Proceedings of 1st ERCIM Blockchain Workshop 2018. European Society for Socially Embedded Technologies (EUSSET).

Hodgins, H. W. (2002). The future of learning objects. Proceedings of the 2002 eTEE Conference, 76-82. Recuperado http://dc.engconfintl.org/cgi/viewcontent.cgi?article=1012\&context=etechnologies 
Holliday, Ó. J. (2012). Sistematización de experiencias, investigación y evaluación: aproximaciones desde tres ángulos. $F(x)=$ Educación Global Research, 1, 56-70.

Iansiti, M., \& Lakhani K. (2017). The truth about Blockchain. Harvard Business Review, 95(1), 118-127

Kemmis, S., McTaggart, R., \& Nixon, R. (2013). The action research planner: Doing critical participatory action research. Geelong: Springer Science and Business Media.

Kurilovas, E., Kubilinskiene, S., \& Dagiene, V. (2014). Web 3.0-Based personalisation of learning objects in virtual learning environments. Computers in Human Behavior, 30, 654-662. Retrieved from: http://bibliografia.eovirtual.com/KurilovasE_2014_Web.pdf

Lata, S. (2017). The Parameters of Teacher's Education. International Journal of Research in Economics and Social Sciences, 7(3), 166-177. Retrieved from: http://euroasiapub.org/wpcontent/uploads/2017/05/20ESSMarch-4620-1.pdf

Lázaro, B., y Obregón, I. (2009). Evaluación de la implementación. Guía práctica 4. Barcelona: Colección Ivalúa de guías practices, Institut Català d'Ávaluació de Polítiques Públiques. Recuperado de: http://www.dgfc.sepg.hacienda.gob.es/sitios/dgfc/esES/ipr/fcp1420/e/Documents/Guia3_Evaluacion_de_implementacion_ivalua.pdf

Liu, M., Kang, J., Zou, W., Lee, H., Pan, Z., \& Corliss, S. (2017). Using Data to Understand How to Better Design Adaptive Learning. Technology, Knowledge and Learning, 22(3), 271-298. Retrieved from: https://link.springer.com/article/10.1007/s10758-017-9326-z

López-Pastor, V. M., Fernández-Balboa, J. M., Santos Pastor, M. L., \& Fraile Aranda, A. (2012). Students' self-grading, professor's grading and negotiated final grading at three university programmes: analysis of reliability and grade difference ranges and tendencies. Assessment \& Evaluation in Higher Education, 37(4), 453-464. Retrieved https://www.tandfonline.com/doi/abs/10.1080/02602938.2010.545868

Masika, R. \& Jones, J. (2016). Building student belonging and engagement: insights into higher education students' experiences of participating and learning together, Teaching in Higher Education, 21(2), 138-150. doi: $10.1080 / 13562517.2015 .1122585$

Narayanan A., Bonneau, J., Felten, E., Miller, A., \& Goldfeder S. (2016). Bitcoin and cryptocurrency technologies: a comprehensive introduction. New York: Princeton University Press.

Padilla, M. C. (2016). Formulación y evaluación de proyectos. Bogotá, Colombia. Ecoe Ediciones.

Rivera-Vargas, P., \& Cobo, C. (2018). Plan Ceibal en Uruguay: una política que conecta inclusión e innovación. En P. Rivera-Vargas, J. Muñoz-Saavedra, R. Morales Olivares y S. Butendieck-Hijerra (Eds), Políticas Públicas para la Equidad Social (pp. 4-29). Santiago de Chile: Colección Políticas Públicas, Universidad de Santiago de Chile. Recuperado de: https://digital.fundacionceibal.edu.uy/jspui/handle/123456789/266

Rivera-Vargas, P., \& Miño-Puigcercós, R. (2018). Young people and virtual communities.: New ways of learning and of social participation in the digital society. Páginas de Educación, 11(1), 67-82. doi: http://dx.doi.org/10.22235/pe.v11i1.1554.

Rivera-Vargas, P., Sancho-Gil, J. M., \& Sánchez, J. A. (2017). Los límites de la disrupción en el orden académico. La cultura DIY en la universidad. Páginas de Educación, 10(2), 127-142. doi: http://dx.doi.org/10.22235/pe.v10i2.1428

Raigada, J. L. P. (2002). Epistemología, metodología y técnicas del análisis de contenido. Sociolinguistic Studies, 3(1), 1-42.

Sapag, N., \& Sapag, R. (2000). Preparación y evaluación de proyectos. DF México: McGraw Hill.

Scribano, A., \& Sena, A. D. (2009). Las segundas partes sí pueden ser mejores: algunas reflexiones sobre el uso de datos secundarios en la investigación cualitativa. Sociologias, 11(22). 100-118

Selwyn, N. (2015). Data entry: towards the critical study of digital data and education. Learning, Media and Technology, 40(1), 64-82. Retrieved http://www.tandfonline.com/doi/abs/10.1080/17439884.2014.921628

Selwyn, N. (2016). Is technology good for education? Hoboken (NJ): John Wiley \& Sons.

Selwyn, N. (2018). Data points: exploring data-driven reforms of education. British Journal of Sociology of Education, 39(5). 1-9. doi: https://doi.org/10.1080/01425692.2018.1469255

Tapscott D., \& Tapscott A. (2016). The Blockchain Revolution. New York: Penguin Random House.

Thomas, D., \& Brown, J. S. (2011). A new culture of learning: Cultivating the imagination for a world of constant change. Lexington, KY: CreateSpace.

Underwood, S. (2016). Blockchain beyond bitcoin. Communications of the ACM, 59(11), 15-17. doi: $10.1145 / 2994581$

Wetherell, M., \& Potter, J. (1998). El análisis del discurso y la identificación de los repertorios interpretativos. En A. Gordo, y J. Linaza, Psicología, Discurso y Poder: Metodologías cualitativas, perspectivas críticas (pp. 63-78). Madrid: Ed. Visor. 